\title{
INDUSTRY 4.0 AND SCIENCE EDUCATION
}

\author{
Bulent Cavas \\ Dokuz Eylul University, Turkey
}

Industry 4.0 and its applications are one of the most important issues of countries that want to keep their competitiveness in the field of scientific, technological and innovation in today's world. The Countries that are not able to adapt to Industry 4.0 processes will not be able to develop scientifically and technologically or keep up with current innovation processes. One of the aims of this paper is to explain the concept of industry 4.0 to our readers in a comprehensible manner and to show how much science education is actually related to industry 4.0.

In a general sense, Industry 4.0 or in other words, the 4th Industrial Revolution is an expression that includes many modern automation processes, large databases that communicate with each other, robotic devices and dark factories, in short, quality production technologies. In addition, Industry 4.0 includes modern technologies such as additive manufacturing, autonomous robots, big data, artificial intelligence, augmented reality, system integration, internet of things, cybersecurity, cloud computing, machine learning, deep learning etc. These technologies play an important role especially in the formation of new smart factories.

Considering the factories that were known in the past, it was seen that there were workers working at the different machines and these workers took part in the control and decision making processes. However, today, there are factories in which even the lights do not light up, and instant decision-making processes are carried out automatically by modern robotic devices. In such factories, the data obtained from all processes are continuously subjected to high level analysis and used to create new business models to increase the efficiency of the factory.

After providing information about the concept and processes of Industry 4.0, it is useful to briefly discuss the historical paradigm in the transition of industry 1.0 to 4.0. Industry 1.0, known as the first industrial revolution, took place between the 18th and 20th centuries and mainly used mechanical production systems using water and steam power. The main objective here is to increase production by increasing the working comfort of workers. Some technologies, such as steam trains, industrial weaving devices, can be defined as industry 1.0 products.

Industry 2.0 had been effective since the early 20th century. The emergence of electricity as an important power source in this period caused the end of the use of water and steam power in the factories. It is one of the important initiatives of this period that the machines required for the factories are designed to use electrical power. At the beginning of this period, the concepts of efficiency and productivity emerged. It has begun to focus on the processes that affect production, such as which worker will work on which machine and what needs have to be paid attention to when the product produced by this worker moves to the next stage. Extra processes to improve product output and quality are considered important functions of the factories.

Industry 3.0 seems to have taken place towards the end of the 20th century. During this period, the discovery of electronic circuits and the integration of these circuits to each other began to make workers' work easier in factories, and in some cases they started to take their place. Towards the end of this period, it is seen that fully automate machines emerged. During the Industry 3.0 period, software requirements appeared to be largely evident. In particular, the software that will work on the developed electronic hardware has gained importance. In addition, more in-depth studies have been carried out on concepts such as product process management, follow-up and operational resources within the factories, and it has been emphasized that digital technology and automation software should be used in place of manual processes. 
ISSN 1648-3898 /Print/

ISSN 2538-7138/Online/

By the time of Industry 4.0 (in the past few decades), a new era of technology has emerged in which machines in factories communicate and interact with each other via the Internet of Things (IoT). In this period, it is seen that machines play an active role in decision-making processes by communicating with instant real data. In this developing process, we see that there are systems in which the factories can plan their production in the most efficient way and they can take control and decide with instant data. It is seen that the factories will increase their production processes through Industry 4.0 to the highest level and in a controlled manner.

In the section above, the industry 1.0 - 4.0 paradigm is tried to be summarized. Maybe, it is better to continue to ask questions to understand the situation between industrial developments and science education: To what extent these developments in the industry have taken place in science education?

In response to this question, we can begin by explaining the change in schools. We can take an example from science classrooms. When the classes in the Industry 1.0 period and today's science classes are examined, it is impossible to say that there have been huge changes. Today, it is seen that most students are still passively trying to understand the information coming from their teachers as much as they can in their classrooms in most countries. The situation was the same in the past. The science topics taught to students are more or less the same when compared. What about the development of phones after invention by Graham Bell in 1876? While it was not possible to call for a person without a cable connection in the past, we are now able to talk as much as we want at any location. In short, we carry high-tech computers in our pockets. It is easy to say that this incredible change in the industry has not been the same in science education.

The second important question can be connected with science education: Current science education in countries in terms of content and capacity provides individuals to meet today's digital expectations?

The importance of science and technology education comes to the forefront at this point, considering that the workers who will work in factories in the future should be equipped with high-level technological knowledge and experience. It is clear that this knowledge and experiences should be provided from the early stages of education. It is very important that qualified manpower equipped with scientific and technological knowledge and experience will increase the competitiveness of that country in science and technology fields. The ministries of education have great responsibilities in training qualified manpower who can adapt to this incredible transformation in the industry. Otherwise, we will have a great number of people who have problems with finding a job which requires any skills.

From this point of view, radical changes in science education are inevitable. Priority should be given to systems where students can produce alternative solutions using the knowledge and skills they have gained, especially when faced with complex scientific problem situations. When developing alternative solutions, students are required to communicate effectively with their friends, teachers and stakeholders in the outside world rather than by individual studies. In addition, high-level thinking skills such as critical thinking and complex problem solving need to be developed.

As a final remark for this paper, it is inevitable that some of the complex skill sets, where even one university degree is not sufficient, will be questioned by the leaders of industry in science and technology. For that reason, individuals who know how to be imaginative, creative, adaptable, flexible will win the race among the others. It is also clear that these skills are easily developed using science education opportunities.

Received: September 20, 2019

Accepted: October 05, 2019

Bulent Cavas
PhD, Professor, Dokuz Eylul University, Distance Education Application and Research Center \& Department of Science Education, Turkey.

E-mail: bulentcavas@gmail.com Website: http://people.deu.edu.tr/bulent.cavas 